\title{
ARTICLE
}

\section{A novel intrinsically microporous ladder polymer and copolymers derived from 1,1',2,2'-tetrahydroxy- tetraphenylethylene for membrane-based gas separation}

Received ooth January 2012, Accepted ooth January 2012

DOI: $10.1039 / x 0 x x 00000 x$

www.rsc.org/

\author{
Xiaohua Ma and Ingo Pinnau*
}

A novel intrinsically microporous polymer was synthesized by polycondensation reaction of 1,1',2,2',-tetrahydroxy-tetraphenylethylene (TPE) and 2,3,5,6-tetrafluoroterephthalonitrile (TFTPN). In addition, a series of copolymers was made from TPE, 5,5',6,6'-tetrahydroxy3,3,3',3'-tetramethylspirobisindane (TTSBI) and TFTPN. All TPE-derived polymers exhibited high molecular weight, good solubility in common organic solvents, high thermal stability and high surface area (550 to $660 \mathrm{~m}^{2} / \mathrm{g}$ ). The $\mathrm{CO}_{2}$ permeability of a methanoltreated and $120^{\circ} \mathrm{C}$ vacuum-dried TPE-TFTPN film was 862 Barrer with a moderate $\mathrm{CO}_{2} / \mathrm{N}_{2}$ selectivity of 26. The selectivity of the TPE-TTSBI-PIMs decreased with increasing TTSBI content coupled with a sharp increase in permeability. Molecular simulations indicated that the introduction of the tetraphenylethylene unit resulted in an increased rotational freedom of dihedral angles in the polymer main chain relative to those of the spirobisindane-based PIM-1.

\section{Introduction}

In recent years, there is an increasing interest in the synthesis of porous polymers, such as conjugated porous polymers, covalent organic frameworks, crosslinked porous polymers and intrinsically microporous polymers. ${ }^{1-3}$ Their microporosity and design flexibility can potentially be exploited in a variety of fields such as catalysis, 2,3 sensors for trace substances detection, ${ }^{4}$ energy conversion and storage, ${ }^{5,6}$ and membranebased separations. ${ }^{7,8}$ Among the above materials, polymers of intrinsic microporosity (PIM) are the most promising porous polymer class for membrane applications, due to their combination of high permeability and selectivity as well as good solution processability. ${ }^{8-10}$

Glassy ladder polymers of intrinsic microporosity were first introduced in 2004 by Mckeown's and Budd's group. ${ }^{9}{ }^{10}$ The state-of-the-art PIM-1 was formed by simple condensation polymerization of $5,5^{\prime}, 6,6^{\prime}$-tetrahydroxy-3,3,3', $3^{\prime}$ tetramethylspirobisindane (TTSBI) and 2,3,5,6tetrafluoroterephthalonitrile (TFTPN). The resulting polymer was composed of rigid ladder-type repeat units including bulky, sterically hindered spirobisindane contortion sites. As a result, PIM-1 showed highly inefficient chain packing with a remarkable microporosity, as determined by nitrogen adsorption measurements at $-196{ }^{\circ} \mathrm{C}\left(\mathrm{S}_{\mathrm{BET}} \sim 800 \mathrm{~m}^{2} / \mathrm{g}\right)$.

PIM-1 exhibited over 100-fold enhanced permeability compared to that of commercial low-free-volume polymers, such as Matrimid, ${ }^{11}$ coupled with a modest selectivity. The gas permeation properties of PIM-1 reached the 2008 Robeson permeability/selectivity upper bound for some gas pairs. ${ }^{12-15}$ Based on the promising results obtained for PIM-1, many other high-performance ladder PIMs, ${ }^{16-29}$ modified prototype PIM$1,{ }^{30-33}$ and PIM polyimides (PIM-PI) ${ }^{34-42}$ have been reported with excellent gas separation properties. In fact, several ladder PIMs $^{25-27}$ and PIM-PIs ${ }^{37,40,41}$ demonstrated much better performance than other known polymers, thereby redefining the previously reported permeability/selectivity upper bound for air and hydrogen separations. ${ }^{27}$ However, in the burgeoning materials class of PIMs there is still a quest for novel customdesigned building blocks to further improve the understanding of structure/property relationships for advanced gas separation membranes.

Tetraphenylethylene (TPE) is a building block widely investigated in aggregation-induced emission (AIE) materials, 
which originated from the restriction of the intramolecular rotation (RIR) effect in the tetraphenylethylene moiety. ${ }^{43}, 44$ TPE is a bulky and sterically hindered group with great potential as a building block for development of novel PIMs for membrane-based separations. In this study, we report for the first time the design and synthesis of tetraphenylethylene-based PIMs, as illustrated in Scheme 1. The detailed synthetic procedure and characterization are provided in the supporting information.
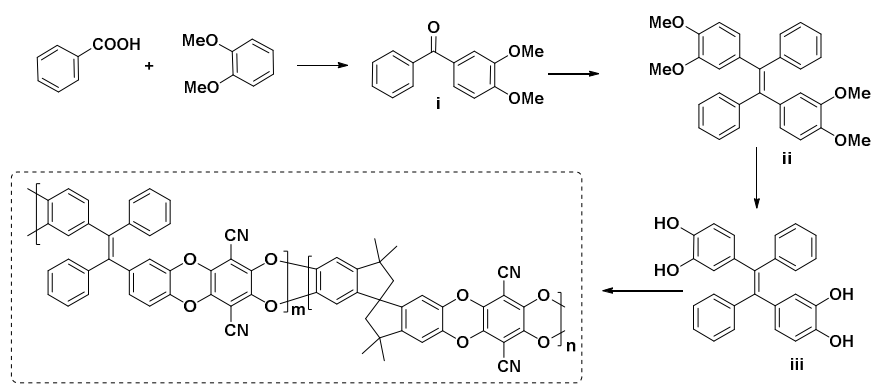

Scheme 1 Design and synthesis of tetraphenylethylene-based homo-PIM and co-PIMs. $\mathrm{m}=1, \mathrm{n}=0$ (TPE-TFTPN); $\mathrm{m}=0, \mathrm{n}=1$ (TTSBI-TFTPN = PIM-1)

\section{Results and Discussion}

(3,4-dimethoxyphenyl) (phenyl)methanone $\mathbf{i}$ was made by a previously reported method ${ }^{22}$ and was then converted to 1,1 ',2,2'-tetramethoxy-tetraphenylethylene via the McMurry reaction in the presence of zinc and $\mathrm{TiCl}_{4}$ as catalyst. ${ }^{45}$ The McMurray reaction for the asymmetric ketone $((3,4-$ dimethoxyphenyl)(phenyl)methanone) resulted in Trans and Cis isomers with a ratio of $85 / 15$. The Trans isomer was separated by column chromatography and the pure product was used for further reactions (Scheme S1 and Fig. S1). The resulting intermediate ii was further demethylated with $\mathrm{BBr}_{3}$, and monomer iii was obtained quantitatively. This monomer and $5,5^{\prime}, 6,6^{\prime}$-tetrahydroxy-3,3,3',3'-tetramethylspirobisindane (TTSBI) were polymerized in different ratios with 2,3,5,6tetrafluoroterephthalonitrile (TFTPN) in DMAc as a solvent and $\mathrm{K}_{2} \mathrm{CO}_{3}$ as a base at $140{ }^{\circ} \mathrm{C}$ for 5 to $10 \mathrm{~min}$. A series of homo- and co-PIMs denoted as TPE-PIM, TPE-75, TPE-50, TPE-25 and PIM-1 were obtained with corresponding TPE ratios of 100, 75, 50, 25 and 0 percent. The ratios of the homoand co-PIMs were characterized and identified by NMR, as shown in Fig. 1.

The resulting co-PIMs demonstrated good solubility in some common solvents such as THF, dichloromethane, chloroform, NMP, DMF, and DMAc, (Table S1). These polymers exhibited high molecular weight $\left(\mathrm{M}_{\mathrm{n}}\right)$, ranging from $3.4 \times 10^{4}$ to $14.5 \times$ $10^{4} \mathrm{~g} / \mathrm{mol}$, coupled with a polydispersity of 2.1 to 3.2 , as determined by GPC using chloroform as solvent. Transparent, yellow films were made by casting a 2-3\% (wt/v) chloroform solution into leveled Petri dishes and evaporating the solvent under ambient conditions. The films were then soaked in methanol for 24 hours to remove any trapped casting solvent. Thereafter, the films were dried at $120^{\circ} \mathrm{C}$ under vacuum for 24 hrs. TGA experiments confirmed that the films were solventfree prior to the gas permeation tests.

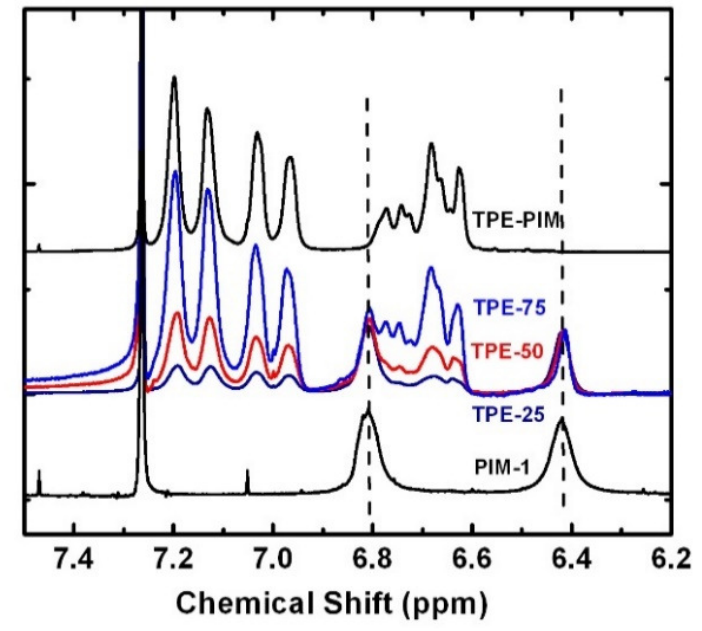

Fig. 1 Proton NMR of TPE-PIM, PIM-1 and TPE-PIM-1 copolymers; the peaks of the copolymers were normalized at $6.41 \mathrm{ppm}$.

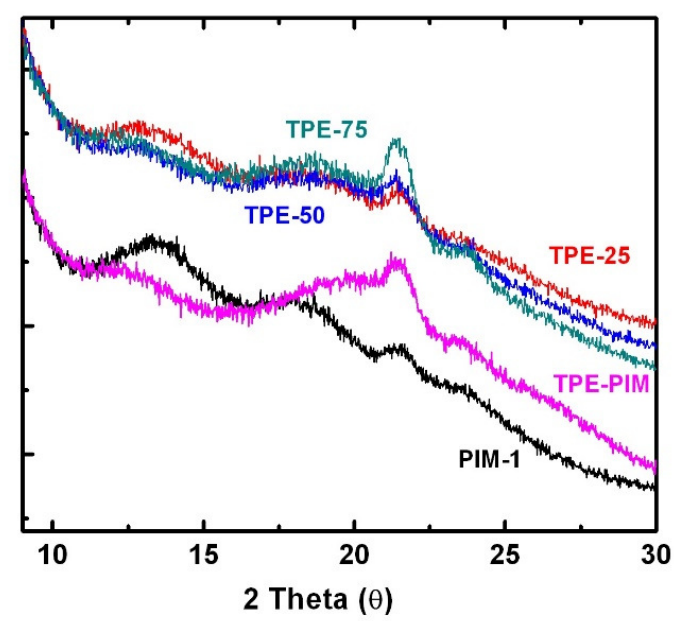

Fig. 2 Wide-angle X-ray scattering of TPE-PIM, TPE-PIM-1, PIM-1 and copolymers. TPE-25, TPE-50 and TPE-75 were normalized and shifted in the y-axial direction above PIM-1 and TPE-PIM.

Table 1 Basic properties of TPE-PIM, PIM-1 and TPE-PIM copolymers.

\begin{tabular}{lccccc}
\hline Polymers & $\begin{array}{c}\mathrm{M}_{\mathrm{n}} \times 10^{-4} \\
(\mathrm{~g} / \mathrm{mol})\end{array}$ & PDI $^{b}$ & $\begin{array}{c}\mathrm{T}_{\mathrm{d}}{ }^{c} \\
\left({ }^{\circ} \mathrm{C}\right)\end{array}$ & $\begin{array}{c}\mathrm{S}_{\text {BET }} \\
\left(\mathrm{m}^{2} / \mathrm{g}\right)\end{array}$ & $\begin{array}{c}\text { Total pore } \\
\text { volume }^{d}\end{array}$ \\
\hline TPE-PIM & 7.83 & 2.3 & 475 & 550 & 0.54 \\
TPE-75 & 3.40 & 3.2 & 465 & 560 & 0.47 \\
TPE-50 & 6.00 & 2.1 & 455 & 600 & 0.45 \\
TPE-25 & 4.90 & 2.3 & 440 & 660 & 0.51 \\
PIM-1 & 14.5 & 2.4 & 430 & 770 & 0.70
\end{tabular}

${ }^{a}$ The molecular weight of the polymers was measured by GPC using chloroform as solvent and polystyrene as external standard. The eluent speed was $1 \mathrm{~mL} / \mathrm{Min} .{ }^{b}$ The PDI was obtained by $\mathrm{M}_{\mathrm{w}} / \mathrm{M}_{\mathrm{n}}$. ${ }^{c}$ The decomposition temperature was selected as the onset decomposition temperature of the TGA curve. ${ }^{\mathrm{d}}$ The total pore volume was obtained at the relative $\mathrm{N}_{2}$ pressure $\left(\mathrm{p} / \mathrm{p}_{0}\right)$ of 0.97 . 
Similar to previously reported microporous PIMs, ${ }^{18}$ all of the homo- and co-PIMs of this study exhibited completely amorphous structures as identified by wide-angle X-ray scattering shown in Fig. 2. TPE-PIM demonstrated tighter chain packing compared with PIM-1, as indicated by the much weaker peak at low-angle around $13.6^{\circ}(\mathrm{d}$-spacing $=6.5 \AA)$, whereas higher intensity is evident at the angle around $20^{\circ}$ (dspacing $=4.4 \AA$ ). As expected, the copolymers show $\mathrm{x}$-ray scattering between those of the homopolymers, depending on the TPE/TTSBI ratio (Fig. 2).

All TPE-based PIMs demonstrated high thermal stability as identified from their onset decomposition temperature over 440 ${ }^{\circ} \mathrm{C}$, as illustrated in Fig. 3. It is interesting to note that TPEPIM had a $40^{\circ} \mathrm{C}$ higher decomposition temperature than PIM1 , most likely due to its higher aromatic content.

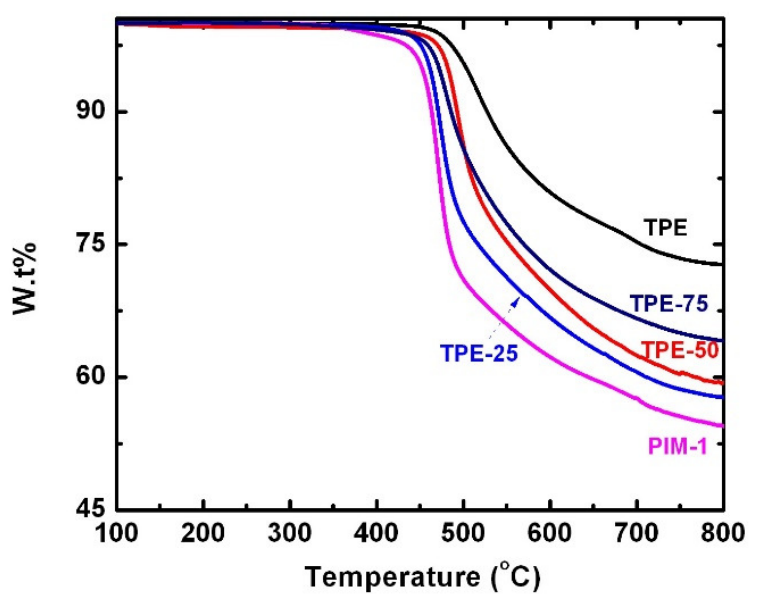

Fig. 3 Thermal gravimetric analysis of the TPE-based PIMs and PIM-1.

The TPE-based PIMs demonstrated high surface area (Table 1), which was calculated from their $\mathrm{N}_{2}$ adsorption isotherms at $196{ }^{\circ} \mathrm{C}$, as illustrated in Fig. 4. All polymers exhibited type I adsorption isotherms characterized by a remarkable sorption uptake at very low relative pressure $\left(\mathrm{p} / \mathrm{p}_{0}<0.01\right)$, indicating the presence of significant microporosity. TPE-PIM had the lowest surface area of $550 \mathrm{~m}^{2} / \mathrm{g}$ of all polymers reported in this study. As the fraction of the spirobisindane repeat unit increased in the copolymers, a significant increase in the adsorption uptake at relatively low pressure $\left(\mathrm{p} / \mathrm{p}_{0}<0.1\right)$ was observed, and the surface area of the TPE-based PIMs increased continuously from $550 \mathrm{~m}^{2} / \mathrm{g}$ (TPE-PIM) to $770 \mathrm{~m}^{2} / \mathrm{g}$ (PIM-1).

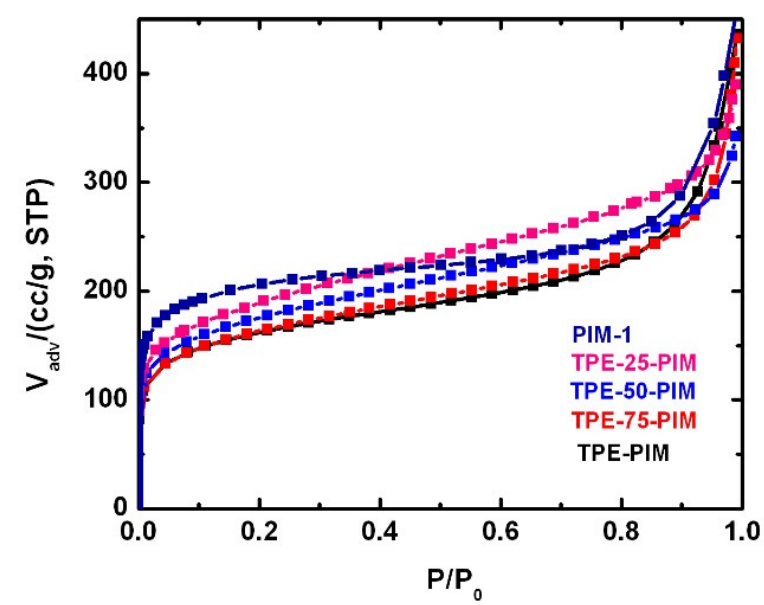

Fig. $4 \mathrm{~N}_{2}$ adsorption isotherms of the TPE-Based PIMs and PIM-1 at $-196{ }^{\circ} \mathrm{C}$.

In order to evaluate the performance of TPE-based PIMs, the gas transport properties of the polymers were analyzed by the constant-volume/variable-pressure method. The data are summarized in Table 2 . The permeability and selectivity values of PIM-1 were similar to those reported by $\mathrm{Du}$ et al. for films made under similar conditions. ${ }^{18}$ A sharp decrease in permeability was observed for all gases when the tetraphenylethylene moiety was substituted for spirobisindane in the PIM copolymers. For example, TPE-PIM had a $\mathrm{CO}_{2}$ permeability of 862 Barrer, which is about 7-fold lower than that of PIM-1. However, there is a concurrent improvement in selectivity, e.g., the selectivity of $\mathrm{O}_{2} / \mathrm{N}_{2}$ and $\mathrm{CO}_{2} / \mathrm{CH}_{4}$ improved from 3.2 to 4.2 and 12 to 21 , respectively. The sequence of the gas permeability of all polymers in this study was $\mathrm{P}_{\mathrm{CO} 2}>\mathrm{P}_{\mathrm{H} 2}>$ $\mathrm{P}_{\mathrm{O} 2}>\mathrm{P}_{\mathrm{CH} 4}>\mathrm{P}_{\mathrm{N} 2}$, which is typically observed for high surface area PIMs. It interesting to note that there is a qualitative correlation between the permeability and the surface area of the polymers, that is, higher BET surface area was coupled with higher gas permeability and lower gas selectivity by increasing the spirobisindane content in the TPE-copolymers (Table 2)

Table 2 Gas permeability and ideal selectivity TPE-PIM, TPE-PIM-1 copolymers and PIM-1 (2bar; $\left.35^{\circ} \mathrm{C}\right)$.

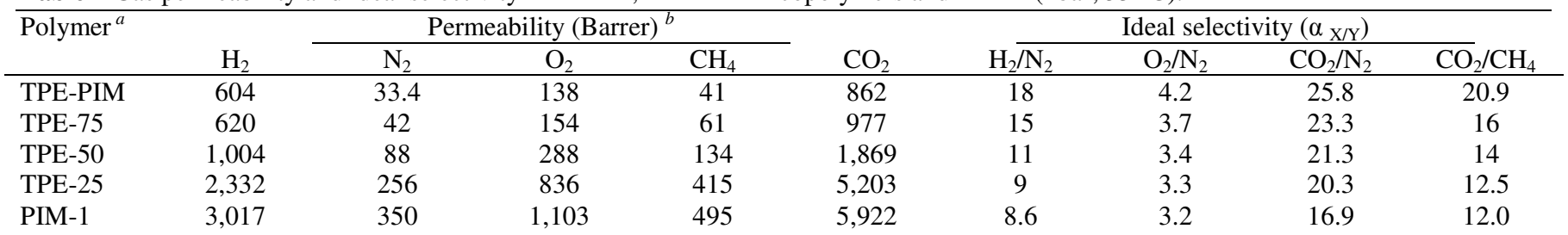

${ }^{a}$ The membranes were cast using chloroform as solvent and soaked in methanol for 24 hours, and thereafter dried under vacuum at $120{ }^{\circ} \mathrm{C}$ for $24 \mathrm{hr}$.

${ }^{b} 1$ Barrer $=10^{-10} \mathrm{~cm}^{3}(\mathrm{STP}) \cdot \mathrm{cm} / \mathrm{cm}^{2} \cdot \mathrm{s} \cdot \mathrm{cmHg}=7.5 \mathrm{x} 10^{-18} \mathrm{~m}^{3}(\mathrm{STP}) \cdot \mathrm{m} / \mathrm{m}^{2} \cdot \mathrm{s} \cdot \mathrm{Pa}$.

The permeability/selectivity trade-off plots for $\mathrm{O}_{2} / \mathrm{N}_{2}$, $\mathrm{CO}_{2} / \mathrm{CH}_{4}, \mathrm{CO}_{2} / \mathrm{N}_{2}$ and $\mathrm{H}_{2} / \mathrm{N}_{2}$ are illustrated in Fig. S2. The TPE-based PIMs and co-PIMs are located below the 2008 and 2015 permeability/selectivity trade-off curves. It is suggested that the rotational freedom of the ethylene bond in the TPEPIM repeat unit leads more efficient polymer packing and, hence lower free volume and permeability. The calculated rotation energies of the dihedral angle of the 
tetraphenylethylene and spirobisindane units are highlighted in Fig. 5. When the dihedral angle was rotated from -180 to $+180^{\circ}$, two energy minima for TPE-PIM, both in the positive dihedral angle at $130^{\circ}$ and negative dihedral angle around $-50^{\circ}$, were observed. In the case of PIM-1, owning to its fused rings structure, only one energy minimum at around $-50^{\circ}$ was observed. Therefore, the conformational freedom of TPE-PIM is much larger than that of PIM-1, resulting in a more densely packed polymer structure.<smiles>CC1Oc2c(C#N)c3c(c(C#N)c2O1)Oc1cc(C(=C(c2ccccc2)C(C)(C)C)c2ccccc2)ccc1O3</smiles><smiles>Cc1cc2c(cc1C)C1(CC2(C)C)CC(C)(C)c2cc3c(cc21)Oc1c(C#N)c2c(c(C#N)c1O3)OC(C)O2</smiles>

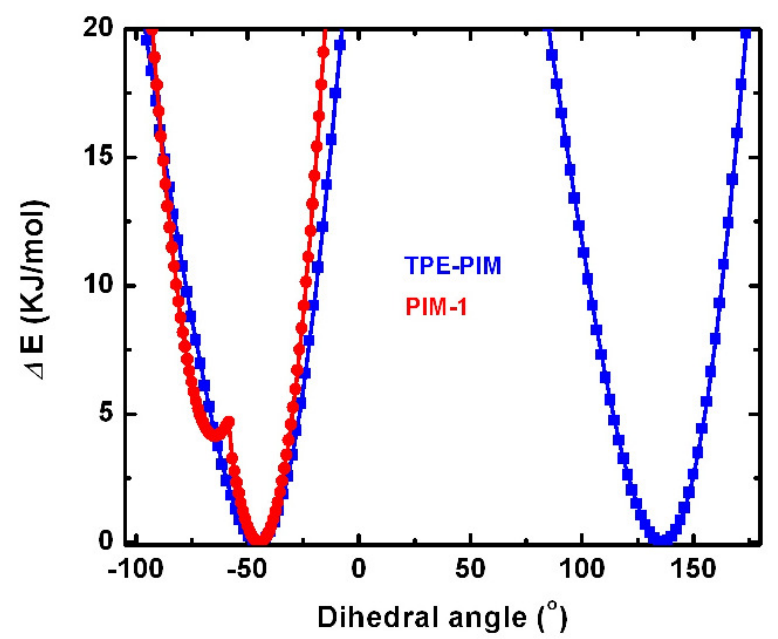

Fig. 5 The rotation angles selected in TPE-PIM (blue) and PIM-1 (red) and their calculated rotation energy against dihedral angle.

\section{Conclusions}

A novel TPE-based monomer was synthesized by the McMurry method and successfully introduced as a building block for the synthesis of polymers of intrinsic microporosity. A TPE-based homopolymer and a series of co-PIMs were made by reaction of TPE with 5,5',6,6'-tetrahydroxy-3,3,3',3'tetramethylspirobisindane (TTSBI) and 2,3,5,6tetrafluoroterephthalonitrile (TFTPN). The amorphous glassy TPE-based PIMs demonstrated good solubility and higher thermal stability than PIM-1. Their BET surface area was in the range of 550 to $660 \mathrm{~m}^{2} / \mathrm{g}$. The TPE-based PIMs showed lower permeability coupled with a moderately enhanced selectivity compared with PIM-1. WXRD results showed a tighter structure of TPE-PIM and its copolymers as indicated by smaller d-spacing values than observed in PIM-1. Molecular simulations demonstrated that TPE-PIMs have more rotational freedom compared to PIM-1, which is likely to be the cause for a denser structure, and hence lower permeability.

\section{Acknowledgements}

This research was supported by KAUST baseline funding for Prof. Ingo Pinnau (BAS/1/1323-01-01).

\section{Notes and references}

Advanced Membranes and Porous Materials Center, Physical Sciences and Engineering Division, Chemical and Biological Engineering
Program, King Abdullah University of Science and Technology, Thuwal 23955-6900, Saudi Arabia

Fax: +966 01280821328

E-mail address: ingo.pinnau@kaust.edu.sa.

$\dagger$ Electronic Supplementary Information (ESI) available: The synthesis details, solubility, membrane formation, testing protocol and upper bound plots of the homo- and co-PIMs for different gas pairs are shown in the supporting information]. See DOI: 10.1039/b000000x/

1. Y. Xu, S. Jin, H. Xu, A. Nagai and D. Jiang, Chem. Soc. Rev., 2013, 42, 8012-8031.

2. D. Wu, F. Xu, B. Sun, R. Fu, H. He and K. Matyjaszewski, Chem. Rev., 2012, 112, 3959-4015.

3. S. Lin, C. S. Diercks, Y. B. Zhang, N. Kornienko, E. M. Nichols, Y. Zhao, A. R. Paris, D. Kim, P. Yang, O. M. Yaghi and C. J. Chang, Science, 2015, 349, 1208-1213.

4. Y. Wang, N. B. McKeown, K. J. Msayib, G. A. Turnbull and I. D. Samuel, Sensors, 2011, 11, 2478-2487.

5. F. Vilela, K. Zhang and M. Antonietti, Energ. Environ. Sci., 2012, 5, 7819.

6. N. Du, H. B. Park, M. M. Dal-Cin and M. D. Guiver, Energ. Environ. Sci., 2012, 5, 7306-7322.

7. N. B. McKeown and P. M. Budd, Chem. Soc. Rev., 2006, 35, 675683.

8. R. W. Baker and B. T. Low, Macromolecules, 2014, 47, 6999-7013.

9. P. M. Budd, E. S. Elabas, B. S. Ghanem, S. Makhseed, N. B. McKeown, K. J. Msayib, C. E. Tattershall and D. Wang, Adv. Mater., 2004, 16, 456-459.

10. P. M. Budd, B. S. Ghanem, S. Makhseed, N. B. McKeown, K. J. Msayib and C. E. Tattershall, Chem. Commun., 2004, 230-231.

11. W. J. Koros and G. K. Fleming, J. Membr. Sci., 1993, 83, 1-80. 
12. P. Budd, K. Msayib, C. Tattershall, B. Ghanem, K. Reynolds, N. McKeown and D. Fritsch, J. Membr. Sci., 2005, 251, 263-269.

13. P. Budd, N. McKeown, B. Ghanem, K. Msayib, D. Fritsch, L. Starannikova, N. Belov, O. Sanfirova, Y. Yampolskii and V. Shantarovich, J. Membr. Sci., 2008, 325, 851-860.

14. L. M. Robeson, J Membr. Sci, 2008, 320, 390-400.

15. L. M. Robeson, Z. P. Smith, B. D. Freeman and D. R. Paul, J. Membr. Sci., 2014, 453, 71-83.

16. N. Du, G. P. Robertson, J. Song, I. Pinnau, S. Thomas and M. D. Guiver, Macromolecules, 2008, 41, 9656-9662.

17. N. Du, G. P. Robertson, I. Pinnau and M. D. Guiver, Macromolecules, 2009, 42, 6023-6030.

18. N. Du, G. P. Robertson, I. Pinnau and M. D. Guiver, Macromolecules, 2010, 43, 8580-8587.

19. M. Carta, K. J. Msayib, P. M. Budd and N. B. McKeown, Org. Lett., 2008, 10, 2641-2643.

20. R. Short, M. Carta, C. G. Bezzu, D. Fritsch, B. M. Kariuki and N. B. McKeown, Chem. Commun., 2011, 47, 6822-6824.

21 M. Carta, P. Bernardo, G. Clarizia, J. C. Jansen and N. B. McKeown, Macromolecules, 2014, 47, 8320-8327.

22. C. G. Bezzu, M. Carta, A. Tonkins, J. C. Jansen, P. Bernardo, F. Bazzarelli and N. B. McKeown, Adv. Mater., 2012, 24, 5930-5933.

23. I. Rose, M. Carta, R. Malpass-Evans, M.-C. Ferrari, P. Bernardo, G. Clarizia, J. C. Jansen and N. B. McKeown, ACS Macro Lett., 2015, 4, 912-915.

24. B. S. Ghanem, N. B. McKeown, P. M. Budd and D. Fritsch, Macromolecules, 2008, 41, 1640-1646.

25. M. Carta, R. Malpass-Evans, M. Croad, Y. Rogan, J. C. Jansen, P. Bernardo, F. Bazzarelli and N. B. McKeown, Science, 2013, 339, 303-307.

26. M. Carta, M. Croad, R. Malpass-Evans, J. C. Jansen, P. Bernardo, G. Clarizia, K. Friess, M. Lanc and N. B. McKeown, Adv. Mater., 2014, 26, 3526-3531.

27. B. S. Ghanem, R. Swaidan, X. H. Ma, E. Litwiller and I. Pinnau, $A d v$. Mater., 2014, 26, 6696-6700.

28. S. Liu, Z. Jin, Y. C. Teo and Y. Xia, J. Am. Chem. Soc., 2014, 136, 17434-17437.

29. Z. G. Wang, X. Liu, D. Wang and J. Jin, Polym. Chem., 2014, 5, 2793.

30. N. Du, G. P. Robertson, J. Song, I. Pinnau and M. D. Guiver, Macromolecules, 2009, 42, 6038-6043.

31. N. Du, H. B. Park, G. P. Robertson, M. M. Dal-Cin, T. Visser, L. Scoles and M. D. Guiver, Nat. Mater., 2011, 10, 372-375.

32. C. R. Mason, L. Maynard-Atem, N. M. Al-Harbi, P. M. Budd, P. Bernardo, F. Bazzarelli, G. Clarizia and J. C. Jansen, Macromolecules, 2011, 44, 6471-6479.

33. C. R. Mason, L. Maynard-Atem, K. W. J. Heard, B. Satilmis, P. M. Budd, K. Friess, M. Lanč, P. Bernardo, G. Clarizia and J. C. Jansen, Macromolecules, 2014, 47, 1021-1029.

34. B. S. Ghanem, N. B. McKeown, P. M. Budd, J. D. Selbie and D. Fritsch, Adv. Mater., 2008, 20, 2766-2771.

35. Y. Rogan, R. Malpass-Evans, M. Carta, M. Lee, J. C. Jansen, P. Bernardo, G. Clarizia, E. Tocci, K. Friess, M. Lanč and N. B. McKeown, J. Mater. Chem. A, 2014, 2, 4874.

36. Z. Wang, D. Wang, F. Zhang and J. Jin, ACS Macro Lett., 2014, 3, $597-601$.
37. X. Ma, B. Ghanem, O. Salines, E. Litwiller and I. Pinnau, ACS Macro Lett., 2015, 4, 231-235.

38. X. Ma, B. Ghanem, O. Salines, E. Litwiller and I. Pinnau, Polym. Chem., 2014, 5, 6914-6922.

39. X. H. Ma, O. Salinas, E. Litwiller and I. Pinnau, Macromolecules, 2013, 46, 9618-9624.

40. B. S. Ghanem, R. Swaidan, E. Litwiller and I. Pinnau, Adv. Mater., 2014, 26, 3688-3692.

41. R. Swaidan, B. Ghanem and I. Pinnau, ACS Macro Lett., 2015, 4, 947-951.

42. Y. B. Zhuang, J. G. Seong, Y. S. Do, H. J. Jo, Z. Cui, J. Lee, Y. M. Lee and M. D. Guiver, Macromolecules, 2014, 47, 3254-3262.

43. Y. Hong, J. W. Lam and B. Z. Tang, Chem. Soc. Rev., 2011, 40, 5361-5388.

44. H. Tong, Y. Hong, Y. Dong, M. Haussler, J. W. Lam, Z. Li, Z. Guo, Z. Guo and B. Z. Tang, Chem. Commun., 2006, 3705-3707.

45. J. E. McMurry and M. P. Fleming, J. Am. Chem. Soc., 1974, 96, 4708-4709. 